\title{
HPLC Quantitative Analysis of Rhein and Antidermatophytic Activity of Cassia fistula Pod Pulp Extracts of Various Storage Conditions
}

\author{
Savita Chewchinda, ${ }^{1}$ Mansuang Wuthi-udomlert, ${ }^{2}$ and Wandee Gritsanapan ${ }^{1}$ \\ ${ }^{1}$ Department of Pharmacognosy, Faculty of Pharmacy, Mahidol University, 447 Sri-Ayudthaya Road, Ratchathevi, \\ Bangkok 10400, Thailand \\ ${ }^{2}$ Department of Microbiology, Faculty of Pharmacy, Mahidol University, 447 Sri-Ayudthaya Road, Ratchathevi, \\ Bangkok 10400, Thailand
}

Correspondence should be addressed to Wandee Gritsanapan; wandee.gri@mahidol.ac.th

Received 24 April 2013; Revised 8 August 2013; Accepted 22 August 2013

Academic Editor: Macit Ilkit

Copyright (C) 2013 Savita Chewchinda et al. This is an open access article distributed under the Creative Commons Attribution License, which permits unrestricted use, distribution, and reproduction in any medium, provided the original work is properly cited.

Cassia fistula is well known for its laxative and antifungal properties due to anthraquinone compounds in the pods. This study quantitatively analyzed rhein in the C. fistula pod pulp decoction extracts kept under various storage conditions using HPLC. The antifungal activity of the extracts and their hydrolyzed mixture was also evaluated against dermatophytes. The contents of rhein in all stored decoction extracts remained more than $95 \%(95.69-100.66 \%)$ of the initial amount $(0.0823 \pm 0.001 \% \mathrm{w} / \mathrm{w})$. There was no significant change of the extracts kept in glass vials and in aluminum foil bags. The decoction extract of $C$. fistula pod pulp and its hydrolyzed mixture containing anthraquinone aglycones were tested against clinical strains of dermatophytes by broth microdilution technique. The results revealed good chemical and antifungal stabilities against dermatophytes of $C$. fistula pod pulp decoction extracts stored under various accelerated and real time storage conditions.

\section{Introduction}

Cassia fistula Linn. (Fabaceae) is native to southern Asia but now widely grown in tropical and subtropical areas as an ornament plant due to its beautiful, bright yellow flowers. Other vernacular names include golden shower, Indian larburnum, and pudding pine tree. C. fistula, a national tree of Thailand, is also known as ratchaphruek or khun in Thai. This plant is abundantly found in every region of the country as a flowering plant. The tree blooms profusely during summer, while the ripe pods are simply collected from the ground and thrown away as waste.

C. fistula pod pulp is widely used in traditional medicines as a purgative/laxative drug and also used against various disorders such as skin diseases, diabetes, and other aliments $[1,2]$. It possesses a mild, pleasant purgative action [3]. Various biological activities of the pod pulp such as antifungal, antibacterial, antioxidant, antileishmanial, antifertility, and hypolipidemic activities were reported [4-8]. The ripe pod pulp contains anthraquinones both in aglycone and glycosidic forms. The major anthraquinone in the pod of C. fistula is rhein (Figures 1 and 2). High concentrations of soluble sugars, volatile oils, and waxy and resinous substances are also found in the pod pulp $[9,10]$.

Dermatophytes are the most frequent pathogens that cause serious skin infection. The incidents have been increasing during last decades among immunocompromised patients such as organ transplant recipients, cancer, and HIV/AIDS patients [11]. Some Cassia species have been reported to treat fungal infection [12]. C. alata, C. fistula, and C. tora are recommended for primary health care in Thailand to treat ringworm and skin diseases. In Thai traditional medicine, laxative pills are obtained by boiling the ripe pod pulp of C. fistula with water. The pod pulp is also applied externally for skin eruption, ulcer, wound, eczema, and ringworm. From the previous study on extraction method 


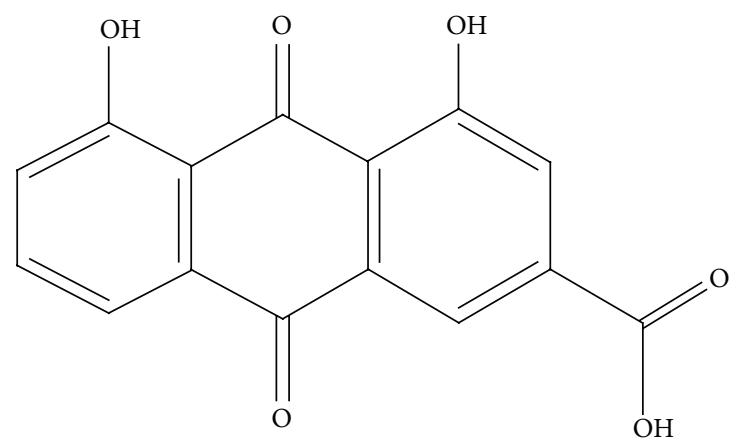

FIGURE 1: Chemical structure of rhein.

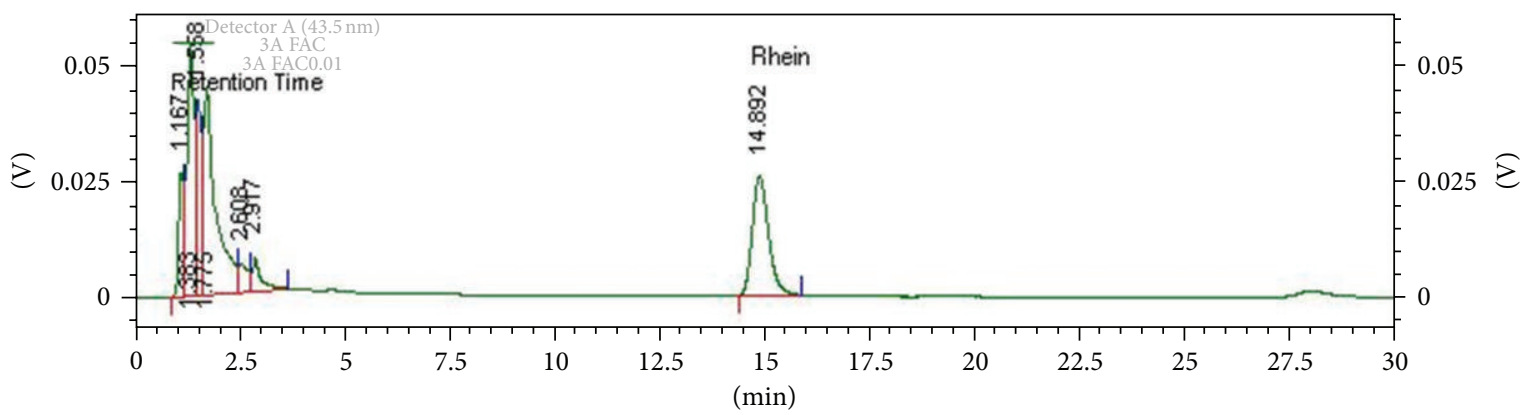

Figure 2: HPLC fingerprints of decoction extract from C. fistula pod pulp (at month 0).

for high content of anthraquinones from C. fistula pod, it revealed that the decoction with water according to Thai traditional use was found to be the appropriate extraction method [13]. Another work [14] reported high antifungal activity of anthraquinone aglycones extracted from glycosidic fraction of Senna alata leaves against clinical strains of dermatophytes. Therefore, it is interesting to determine and compare antidermatophytic activity of the decoction extract from C. fistula pod pulp and its hydrolyzed mixture that contained anthraquinone aglycones, to find a better antidermatophytic raw material from natural sources. The aims of this study were to determine rhein content in $C$. fistula pod pulp decoction extracts stored under real time storage and accelerated conditions and evaluate the antifungal activities against dermatophytes of these stored extracts and their hydrolyzed mixtures to indicate the chemical and biological stabilities of the extract from C. fistula pods. The contents of rhein in the extracts were analyzed using the validated HPLC method [15]. Antidermatophytic activities of the stored decoction extracts and their hydrolyzed mixtures were determined against Trichophyton mentagrophytes, Trichophyton rubrum, and Microsporum gypseum.

\section{Materials and Methods}

2.1. Plant Materials. The ripe pods of C. fistula were collected from Mahasarakham province in the northeastern part of Thailand in April 2010. They were identified by comparing with herbariums at The Forest Herbarium, Department of National Park, Wildlife and Plant Conservation, Ministry of
Natural Resources and Environment, Bangkok. The voucher specimen (WCF0410) was deposited at Department of Pharmacognosy, Faculty of Pharmacy, Mahidol University. The ripe pods were cleaned with tap water and the pod pulp (without seed) was separated and kept in a tight container at $4^{\circ} \mathrm{C}$ until used.

2.2. Preparation of C. fistula Pod Pulp Extract. Fresh pulp of $C$. fistula ripe pod ( $20 \mathrm{~g})$ was boiled with distilled water $(200 \mathrm{~mL})$ for one hour at $95-98^{\circ} \mathrm{C}$, and the mixture was filtered. The extraction process was repeated until anthraquinones in the pulp were exhaustively extracted (tested by Borntrager's reaction). The filtrates were combined and evaporated to dryness on a boiling water bath to yield a decoction crude extract. Yield of the crude extract was recorded, and the extract ratio (weight of pod pulp:1g extract) was calculated.

2.3. Preparation of Extract Containing Anthraquinone Aglycones from C. fistula Pod Pulp Extract. The extraction process was modified from the assay procedure of hydroxyanthracene derivatives of Cassia alata described in the Standard of ASEAN Herbal Medicine, 1993 [16]. Ferric chloride hexahydrate solution of $10.5 \% \mathrm{w} / \mathrm{v}(20 \mathrm{~mL})$ was added to the $C$. fistula pod pulp extract then refluxed for $20 \mathrm{~min}$. The solution was added with concentrated $\mathrm{HCl}(1 \mathrm{~mL})$ and refluxed for another $20 \mathrm{~min}$ then filtered after cooling down. The filtrate was shaken with $3 \times 20 \mathrm{~mL}$ of chloroform in a separating funnel. The chloroform layer was combined and washed with 
$2 \times 15 \mathrm{~mL}$ of distilled water, then evaporated to dryness to yield the hydrolyzed mixture containing anthraquinone aglycones.

\subsection{Stability Studies of C. fistula Pod Pulp Extract}

2.4.1. Stability Study Condition. Three batches of C. fistula pod pulp decoction extract were kept in glass vials and aluminum foil bags at the accelerated $\left(40^{\circ} \mathrm{C} \pm 2^{\circ} \mathrm{C} / 75 \% \mathrm{RH}\right.$ $\pm 5 \% \mathrm{RH})$ and real time storage conditions $\left(30^{\circ} \mathrm{C} \pm 2^{\circ} \mathrm{C} / 75 \%\right.$ $\mathrm{RH} \pm 5 \% \mathrm{RH}$ ) for 6 months as described in ASEAN guideline on stability study of drug product, 2005 [17]. The samples were taken for quantitative analysis of rhein content and determination of their antifungal ability at 0,3 , and 6 months after storage.

2.4.2. Chemical Stability Evaluation. The decoction extract of C. fistula pod pulp of each storage condition was analyzed for rhein content using HPLC [15]. The peak areas of rhein standard and samples indicated the content of rhein in each sample.

2.4.3. HPLC Apparatus and Chromatographic Conditions. HPLC was performed on a Shimadzu Technologies modular model Class VP system consisting of a SCL-10A system, a UV-vis SPD-10A detector, LC-10 AD, and auto injector SIL10A (Shimadzu, Japan). The analysis was carried out using a BDS Hypersil C18 column $(250 \times 4.6 \mathrm{~mm}$, i.d. $5 \mu \mathrm{m})$ (Thermo Fisher Scientific Inc., USA) with a BDS Hypersil C18 guard column $(10 \times 4 \mathrm{~mm}$, i.d. $5 \mu \mathrm{m})$ (Thermo Hypersil-Keystone, USA). The isocratic mobile phase was $0.5 \%$ aqueous acetic acid solution and methanol $(40: 60)$. The total running time was $30 \mathrm{~min}$, and a flow rate was $1.0 \mathrm{~mL} / \mathrm{min}$. The UV detector monitored at $435 \mathrm{~nm}$, while the injection volume was $20 \mu \mathrm{L}$.

2.4.4. Standard Solution Preparation. The rhein reference standard (Sigma, USA) was accurately weighed for preparing stock solution $(1.0 \mathrm{mg} / \mathrm{mL})$. Standard working solution of rhein was prepared by diluting the stock solution with $60 \%$ $(\mathrm{v} / \mathrm{v})$ methanol in the range of $1.25-20 \mu \mathrm{g} / \mathrm{mL}$.

2.4.5. Sample Preparation. Each sample of C. fistula pod pulp decoction extract stored under various conditions was accurately weighed $(0.1 \mathrm{~g})$, dissolved in $60 \%(\mathrm{v} / \mathrm{v})$ methanol, and adjusted to $10 \mathrm{~mL}$ in a volumetric flask. The solution was filtered through a $0.45 \mu \mathrm{m}$ nylon membrane filter and analyzed in triplicate.

\subsection{Antifungal Assay}

2.5.1. Inoculum Preparation. Clinical isolated strains of $T$. mentagrophytes, T. rubrum, and M. gypseum were used in this experiment. Clinical strains identification were based on macroscopic and microscopic examination of cultures. Prior to testing, the strains were separately inoculated on Sabouraud dextrose agar plates and incubated at $28^{\circ} \mathrm{C}$ for 7 days to ensure the viability and purity of the inoculum. $T$. mentagrophytes DMST 19735 (DMST: Department of Medical
Sciences Type culture collection, Thailand) was included as a reference strain.

2.5.2. Determination of Minimum Inhibitory Concentration. Antifungal activities of rhein standard (Sigma, USA), decoction extracts of $C$. fistula pod pulp stored under each storage condition, and their hydrolyzed mixture containing anthraquinone aglycones were tested by broth microdilution assay for antifungal susceptibility in accordance with the Clinical and Laboratory Standard Institute guidelines in the M38-A document on filamentous fungi [18] with modified incubation temperature. Briefly, in U-shaped 96 wells plate, each well was filled with $100 \mu \mathrm{L}$ of the twofold serially diluted test samples and $100 \mu \mathrm{L}$ of the fungal spore suspension to obtain final concentration of inoculum at 1 to $3 \times 10^{3} \mathrm{CFU} / \mathrm{mL}$. Growth control was filled with $100 \mu \mathrm{L}$ of the inoculum and $100 \mu \mathrm{L}$ of RPMI 1640 medium. Each sample was tested in duplicate, while ketoconazole was used as a positive control. The MICs, the lowest concentration of the sample which shows no visible growth after incubation at $28^{\circ} \mathrm{C}$ for 4 days, of rhein, decoction extracts, and their hydrolyzed mixtures containing anthraquinone aglycones while the MICs of ketoconazole were defined as approximately $80 \%$ of inhibition when compared to growth control results.

\section{Results and Discussion}

According to the evaluation criteria of ASEAN guideline on stability study of drug product, 2005, significant change is defined as more than $5 \%$ difference from its initial value. Rhein contents in the decoction extracts of C. fistula pod pulp kept under various storage conditions determined by HPLC were found in the range of $0.0788 \pm 0.005$ to $0.0823 \pm 0.001 \%$ w/w (Table 1).

The rhein contents remained more than 95\% when compared with the initial amount. The results showed no significant change of the extracts kept in glass vials and in aluminum foil bags for 6 months, and the acceptance criteria were met. This indicates good chemical stability of the $C$. fistula pod pulp decoction extract. Storage of the decoction extract in glass vials or in aluminum foil bags promoted no difference on the chemical stability of the extract.

For antifungal assay, many reports [19-21] showed no difference on the MIC of isolates incubated at 28 and $35^{\circ} \mathrm{C}$. Moreover, dermatophyte strains show optimal growth between 4 and 15 days of incubation at $28-30^{\circ} \mathrm{C}$ [22]. Thus, the incubation temperature for the broth microdilution assay of antifungal susceptibility testing in this study was performed at $28^{\circ} \mathrm{C}$ instead of $35^{\circ} \mathrm{C}$.

The decoction extracts of $C$. fistula pod pulp kept under various storage conditions showed very low antifungal activity (MIC $>1,000 \mu \mathrm{g} / \mathrm{mL}$ ). The MICs of hydrolyzed mixtures and rhein standard are shown in Table 1. Anthraquinone aglycones in the hydrolyzed mixtures could inhibit the growth of T. mentagrophytes DMST 19735, T. mentagrophytes and $M$. gypseum at the same MIC of $500 \mu \mathrm{g} / \mathrm{mL}$, and T. rubrum at MIC of $250 \mu \mathrm{g} / \mathrm{mL}$. Whereas rhein standard showed better activities against all tested dermatophytes at the same MIC of 
TABLE 1: The content of rhein in the decoction extract and antifungal activity against dermatophytes of the decoction extract and its hydrolyzed mixture containing anthraquinone aglycones of $C$. fistula pod pulp kept under various storage conditions of stability studies.

\begin{tabular}{|c|c|c|c|c|c|c|c|c|c|}
\hline \multirow[t]{2}{*}{$\begin{array}{l}\text { Time } \\
\text { (month) }\end{array}$} & \multirow[t]{2}{*}{ Packaging } & \multirow[t]{2}{*}{$\begin{array}{c}\text { Storage } \\
\text { condition }\end{array}$} & \multirow[t]{2}{*}{$\begin{array}{l}\text { Rhein content }{ }^{\mathrm{a}} \\
\quad(\% \mathrm{w} / \mathrm{w})\end{array}$} & \multicolumn{2}{|c|}{$\begin{array}{c}\text { T. mentagrophytes DMST } \\
19735 \text { and T. mentagrophytes } \\
\text { MIC }(\mu \mathrm{g} / \mathrm{mL})\end{array}$} & \multicolumn{2}{|c|}{$\begin{array}{c}\text { T. rubrum } \\
\text { MIC }(\mu \mathrm{g} / \mathrm{mL})\end{array}$} & \multicolumn{2}{|c|}{$\begin{array}{l}\text { M. gypseum } \\
\text { MIC }(\mu \mathrm{g} / \mathrm{mL})\end{array}$} \\
\hline & & & & $\begin{array}{c}\text { Decoction } \\
\text { extract }\end{array}$ & $\begin{array}{l}\text { Hydrolyzed } \\
\text { mixture }\end{array}$ & $\begin{array}{c}\text { Decoction } \\
\text { extract }\end{array}$ & $\begin{array}{l}\text { Hydrolyzed } \\
\text { mixture }\end{array}$ & $\begin{array}{c}\text { Decoction } \\
\text { extract }\end{array}$ & $\begin{array}{l}\text { Hydrolyzed } \\
\text { mixture }\end{array}$ \\
\hline 0 & & & $\begin{array}{c}0.0823 \pm 0.001 \\
(100.00 \%)^{\mathrm{b}}\end{array}$ & $>1000$ & 500 & $>1000$ & 250 & $>1000$ & 500 \\
\hline \multirow{4}{*}{3} & Glass vial & Real time & $\begin{array}{c}0.0829 \pm 0.001 \\
(100.66 \%)\end{array}$ & $>1000$ & 500 & $>1000$ & 250 & $>1000$ & 500 \\
\hline & $\begin{array}{l}\text { Aluminum } \\
\text { foil }\end{array}$ & Real time & $\begin{array}{c}0.0815 \pm 0.001 \\
\quad(98.96 \%)\end{array}$ & $>1000$ & 500 & $>1000$ & 250 & $>1000$ & 500 \\
\hline & Glass vial & Accelerated & $\begin{array}{c}0.0817 \pm 0.003 \\
\quad(99.25 \%)\end{array}$ & $>1000$ & 500 & $>1000$ & 250 & $>1000$ & 500 \\
\hline & $\begin{array}{l}\text { Aluminum } \\
\text { foil }\end{array}$ & Accelerated & $\begin{array}{c}0.0809 \pm 0.002 \\
(98.23 \%) \\
\end{array}$ & $>1000$ & 500 & $>1000$ & 250 & $>1000$ & 500 \\
\hline \multirow{4}{*}{6} & Glass vial & Real time & $\begin{array}{c}0.0791 \pm 0.002 \\
(96.11 \%)\end{array}$ & $>1000$ & 500 & $>1000$ & 250 & $>1000$ & 500 \\
\hline & $\begin{array}{l}\text { Aluminum } \\
\text { foil }\end{array}$ & Real time & $\begin{array}{c}0.0794 \pm 0.001 \\
(96.46 \%)\end{array}$ & $>1000$ & 500 & $>1000$ & 250 & $>1000$ & 500 \\
\hline & Glass vial & Accelerated & $\begin{array}{c}0.0790 \pm 0.001 \\
\quad(95.95 \%)\end{array}$ & $>1000$ & 500 & $>1000$ & 250 & $>1000$ & 500 \\
\hline & $\begin{array}{l}\text { Aluminum } \\
\text { foil }\end{array}$ & Accelerated & $\begin{array}{c}0.0788 \pm 0.005 \\
\quad(95.69 \%)\end{array}$ & $>1000$ & 500 & $>1000$ & 250 & $>1000$ & 500 \\
\hline
\end{tabular}

${ }^{\mathrm{a}}$ Expressed as mean $\pm \mathrm{SD}(n=3)$ and ${ }^{\mathrm{b}}$ content of rhein in C. fistula decoction extract calculated as $100 \%$ at day 0 . Real time $=30^{\circ} \mathrm{C} \pm 2{ }^{\circ} \mathrm{C} / 75 \% \mathrm{RH} \pm 5 \% \mathrm{RH}$. Accelerated $=40^{\circ} \mathrm{C} \pm 2^{\circ} \mathrm{C} / 75 \% \mathrm{RH} \pm 5 \% \mathrm{RH}$.

$125 \mu \mathrm{g} / \mathrm{mL}$. For the drug control, ketoconazole, its inhibitions against T. mentagrophytes DMST 19735, T. mentagrophytes, T. rubrum, and $M$. gypseum were found at MICs of $2,1,1$, and $2 \mu \mathrm{g} / \mathrm{mL}$, respectively. Our results on antifungal activity of the hydrolyzed extracts containing anthraquinone aglycones from C. fistula pod pulp were correlated with the previous study of Duraipandiyan and Ignacimuthu 2010 [23] that rhein from $C$. fistula flower exhibited good activity against dermatophytes. Also, the data confirmed the report on $S$. alata leaves that anthraquinone aglycones promoted better antidermatophytic activity than anthraquinone glycosides [14]. This work supported the traditional use of $C$. fistula pods as a drug for treatment of fungal skin diseases.

\section{Conclusions}

The decoction extract of C. fistula pod pulp, which contains high amount of soluble sugars, showed very low antidermatophytic activity but its hydrolyzed mixture containing anthraquinone aglycones was active against all dermatophytes: T. mentagrophytes DMST 19735, T. mentagrophytes, T. rubrum, and M. gypseum. The decoction extract of $C$. fistula pod pulp was chemically stable after 6 months of storage under the accelerated and real time storage conditions. This could be implied that C. fistula pod pulp decoction extract should enable a tentative shelf life of 24 months [24]. Glass vials and aluminum foil bags promoted no difference on the chemical and antifungal stabilities of the pod pulp extracts. The hydrolyzed pod pulp mixture with anthraquinone aglycones should be selected for fungal treatment. Anyhow, chemical and antifungal stabilities of the stored hydrolyzed extracts under various storage conditions should be further studied to be assured.

\section{Acknowledgment}

This project is part of a Ph.D. thesis of Mahidol University, financially supported by the Office of the Higher Education Commission and Mahidol University under the National Research Universities Initiative. The authors thank Mr. Panupon Khumsupan for his kind proofreading of the paper.

\section{References}

[1] L. V. Asolkar, K. K. Kakkar, and O. J. Chakre, Second Supplement to Glossary of Indian Medicinal Plant with Active Principles, Publication and Information Directorate; CSIR, New Delhi, India, 1992.

[2] M. M. Alam, M. B. Siddiqui, and W. Husain, "Treatmet of diabetes through herbal drugs in rural India," Fitoterapia, vol. 61, no. 3, pp. 240-242, 1990.

[3] T. Bahorun, V. S. Neergheen, and O. I. Aruoma, "Phytochemical constituents of Cassia fistula," African Journal of Biotechnology, vol. 4, no. 13, pp. 1530-1540, 2005.

[4] V. Duraipandiyan and S. Ignacimuthu, "Antibacterial and antifungal activity of Cassia fistula L.: an ethnomedicinal plant," Journal of Ethnopharmacology, vol. 112, no. 3, pp. 590-594, 2007.

[5] P. Siddhuraju, P. S. Mohan, and K. Becker, "Studies on the antioxidant activity of Indian Laburnum (Cassia fistula L.): 
a preliminary assessment of crude extracts from stem bark, leaves, flowers and fruit pulp," Food Chemistry, vol. 79, no. 1, pp. 61-67, 2002.

[6] P. Sartorelli, S. P. Andrade, M. S. C. Melhem, F. O. Prado, and A. G. Tempone, "Isolation of antileishmanial sterol from the fruits of Cassia fistula using bioguided fractionation," Phytotherapy Research, vol. 21, no. 7, pp. 644-647, 2007.

[7] S. Bharadwaj and R. Mathur, "Antifertility screening of fruit of Cassia fistula in female albino rates," Comparative Physiology \& Ecology, vol. 4, pp. 277-279, 1979.

[8] U. C. Gupta and G. C. Jain, "Study on hypolipidemic activity of Cassia fistula legume in rats," Asean Journal of Experimental Sciences, vol. 23, no. 1, pp. 241-248, 2009.

[9] M. M. A. Rizvi, M. Irshad, G. El Hassadi, and S. B. Younis, "Bioefficacies of Cassia fistula: an Indian labrum," African Journal of Pharmacy and Pharmacology, vol. 3, no. 6, pp. 287292, 2009.

[10] N. N. Barthakur, N. P. Arnold, and I. Alli, "The Indian laburnum (Cassia fistula L.) fruit: an analysis of its chemical constituents," Plant Foods for Human Nutrition, vol. 47, no. 1, pp. 55-62, 1995.

[11] M. A. Pfaller, P. G. Pappas, and J. R. Wingard, "Invasive fungal pathogens: current epidemiological trends," Clinical Infectious Diseases, vol. 43, no. 1, pp. S3-S14, 2006.

[12] S. V. Agarkar and D. R. Jadge, "Phytochemical and pharmacological investigations of Genus Cassia: a review," Asian Journal of Chemistry, vol. 11, no. 2, pp. 295-299, 1999.

[13] A. Sakulpanich and W. Gritsanapan, "Extraction method for high content of anthraquinones from Cassia fistula pods," Journal of Health Research, vol. 22, no. 4, pp. 167-172, 2008.

[14] M. Wuthi-udomlert, P. Kupittayanant, and W. Gritsanapan, "In vitro evaluation of antifungal activity of anthraquinone derivatives of Senna alata," Journal of Health Research, vol. 24, no. 3, pp. 117-122, 2010.

[15] S. Chewchinda, A. Sakulpanich, P. Sithisarn, and W. Gritsanapan, "HPLC analysis of laxative rhein content in Cassia fistula pods of different provenances in Thailand," Thai Journal of Agricultural Science. In press.

[16] ASEAN Countries, Standard of ASEAN Herbal Medicines, vol. 1, Aksara Buana, Jakarta, Indonesia, 1993.

[17] ASEAN Countries, "ASEAN Guideline on stability study of drug product," Proceedings of the 9th ACCSQ-PPWG Meeting, Manila, Philippines, 2005.

[18] National Committee for Clinical Laboratory Standards, Reference Method for Broth Dilution Antifungal Susceptibility Testing of Filamentous Fungi. Approved Standard M38-A, National Committee for Clinical laboratory Standards, Wayne, Pa, USA, 2002.

[19] B. Fernández-Torres, F. J. Cabañes, A. J. Carrillo-Muñoz et al., "Collaborative evaluation of optimal antifungal susceptibility testing conditions for dermatophytes," Journal of Clinical Microbiology, vol. 40, no. 11, pp. 3999-4003, 2002.

[20] D. A. Santos and J. S. Hamdan, "Evaluation of broth microdilution antifungal susceptibility testing conditions for Trichophyton rubrum," Journal of Clinical Microbiology, vol. 43, no. 4, pp. 1917-1920, 2005.

[21] M. E. D. S. Barros, D. D. A. Santos, and J. S. Hamdan, "In vitro methods for antifungal susceptibility testing of Trichophyton spp," Mycological Research, vol. 110, no. 11, pp. 1355-1360, 2006.

[22] G. S. de Hoog, J. Guarro, J. Gené, and M. J. Figueras, Atlas of Clinical Fungi, Centralbureau voor Schimmelcultures, Utrecht, The Netherlands, 2nd edition, 2000.
[23] V. Duraipandiyan and S. Ignacimuthu, "Antifungal activity of rhein isolated from Cassia fistula L. flower," WebmedCentral, vol. 1, no. 9, Article ID WMC00687, 2010.

[24] WHO Expert Committee on Specifications for Pharmaceutical Preparations. 


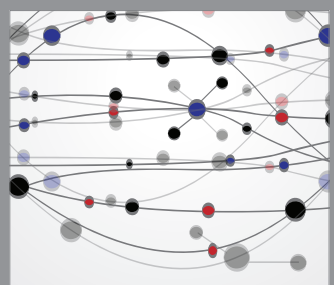

The Scientific World Journal
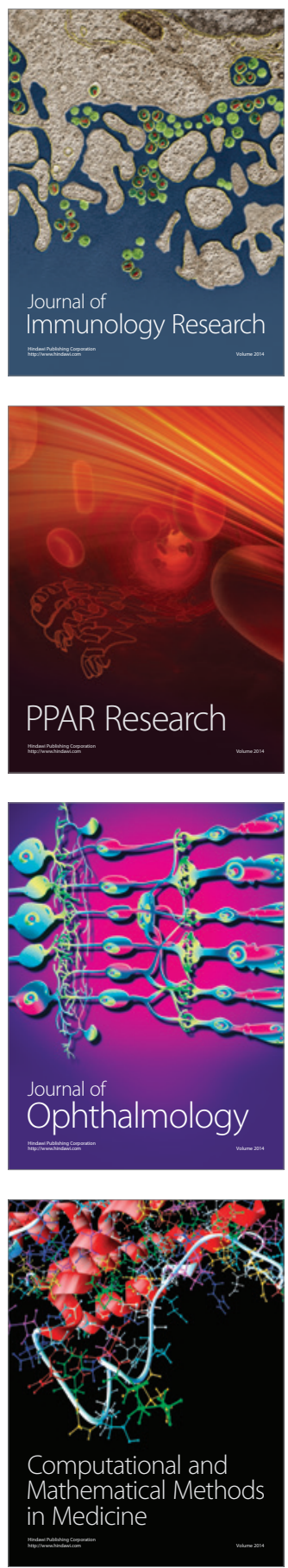

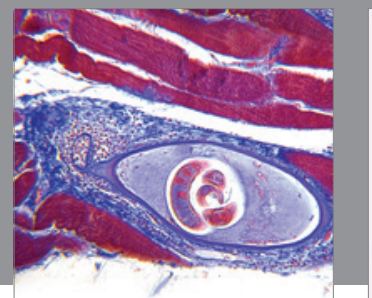

Gastroenterology

Research and Practice
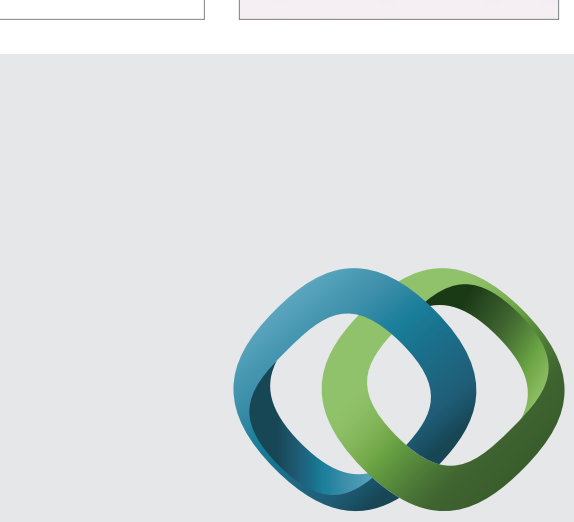

\section{Hindawi}

Submit your manuscripts at

http://www.hindawi.com
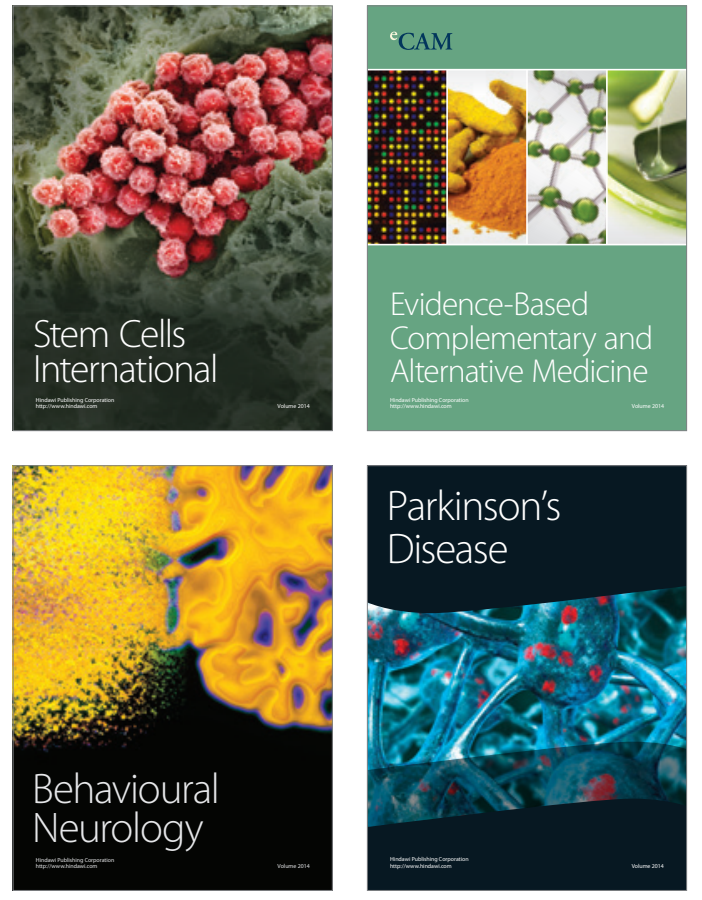
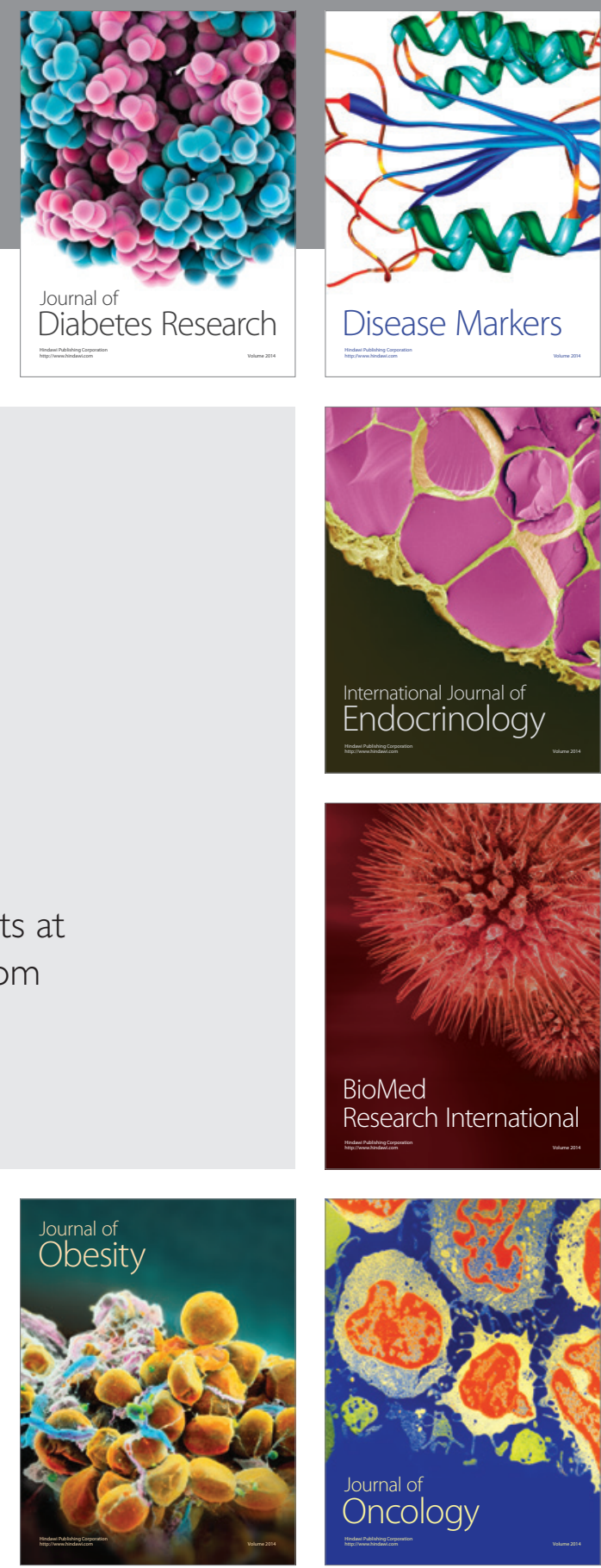

Disease Markers
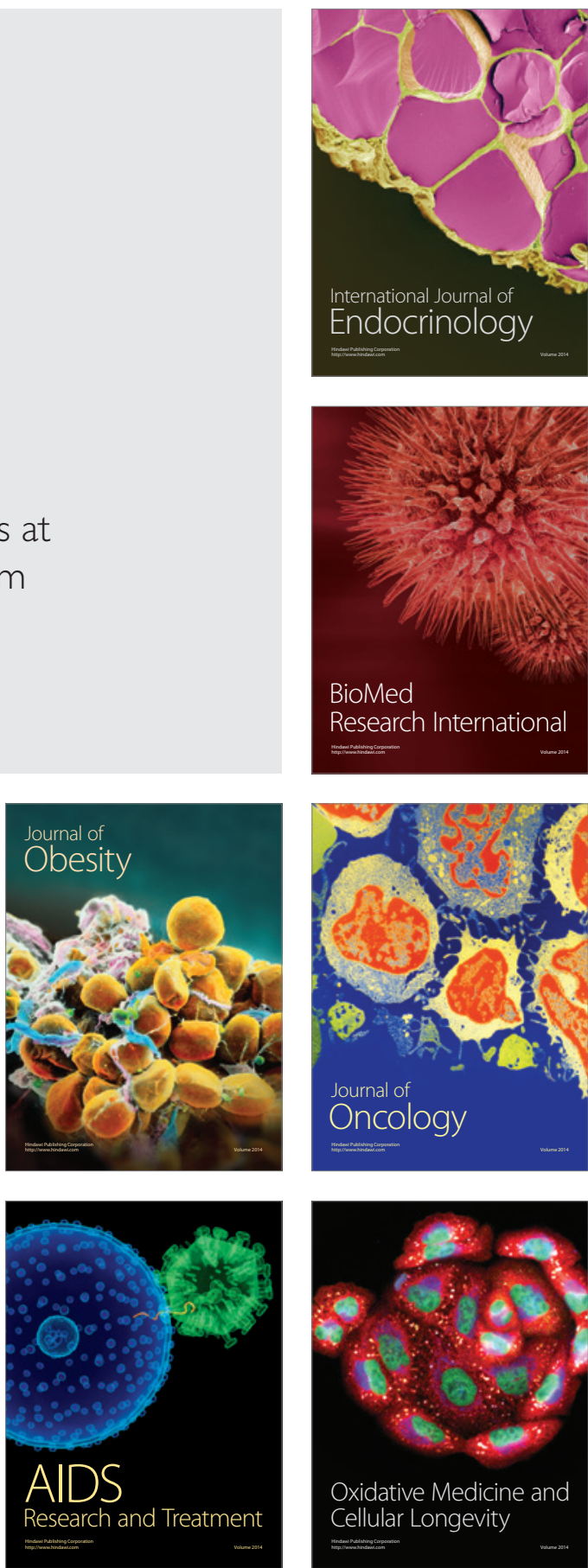